\title{
Hair-on-End Sign in a 9-Year-Old Girl Presenting with Acute Stroke in Sickle Cell Disease
}

\author{
Eugene Ogwang', Charles Newton Odongo $\mathbb{D}^{2}$, Jane Namusisi ${ }^{3}$, Patrick Ambrose Okello', \\ Moses Acan'
}

'Department of Radiology, Mbarara University of Science and Technology, Mbarara City, South-Western Uganda, Uganda; ${ }^{2}$ Department of Surgery, Mbarara University of Science and Technology, Mbarara City, South-Western Uganda, Uganda; ${ }^{3}$ Department of Paediatrics and Child Health, Mbarara University of Science and Technology, Mbarara City, South-Western Uganda, Uganda

Correspondence: Eugene Ogwang, Department of Radiology, Mbarara University of Science and Technology, Mbarara City, South-Western Uganda, Uganda, Tel +25677384I I 20, Email eugenecrystal5@gmail.com

Background: The hair-on-end (HOE) sign is a rare finding seen in the diploic space on skull radiographs, computed tomography (CT) and magnetic resonance imaging (MRI) with the appearance of long, thin vertical striations of calcified spicules perpendicular to the bone surface that looks like hair standing on end. It is classically seen in children/adolescents with hemolytic anemias, in particular, thalassemia major and sickle cell disease. Here, we present a 9-year-old Ugandan girl who presented with stroke in whom head CT demonstrated cerebral intraparenchymal hemorrhage and multiple infarcts on the left with HOE sign. Hb electrophoresis confirmed the diagnosis of sickle cell anemia.

Case Summary: We present a 9-year-old Ugandan girl who presented with an unexplained stroke that preceded an episode of acute headache, vomiting, followed by focal convulsions and altered consciousness. Clinical findings revealed severe pallor of the conjunctivae and mild scleral icterus. CT demonstrated right cerebral intraparenchymal hemorrhage, multiple high cerebral infarcts on the right and evidence of extra medullary hematopoiesis with a classical HOE sign. Hemoglobin (Hb) electrophoresis confirmed sickle cell disease (SCD). The child was then initiated on hydroxyurea, antibiotics, analgesics and intravenous fluids. She improved and was discharged 16 days later. Follow-up of the child was uneventful.

Conclusion: HOE sign is a complication of chronic hemolysis usually seen in patients with thalassemia and sickle cell anemia. It is a rare finding that clinicians should be well conversant with, especially in Africa where sickle cell disease is common.

Keywords: hair-on-end, sickle cell disease, sickle cell anemia

\section{Introduction}

Hair-on-end (HOE) sign is a complication of chronic hemolysis usually seen in patients with sickle cell disease (SCD). SCD refers to any one of the syndromes in which the sickle mutation is co-inherited with a mutation at the other beta globin allele that reduces normal beta globin production. These syndromes include sickle cell anemia (homozygous sickle mutation), sickle-beta thalassemia, hemoglobin SC disease, and others. Sickle cell anemia is the most severe form and it occurs most commonly in patients of African origin and affects approximately $0.2 \%$ of African Americans. ${ }^{1,2}$

When deoxygenated, the abnormal form of hemoglobin, called HbS, aggregates into long chains with consequent irreversible deformation of erythrocytes into a sickle shape. The sickled red cells have reduced flexibility, increased adhesivity, and shortened life span. ${ }^{1,3}$ The multiple clinical manifestations and complications of sickle cell anemia are related to hemolytic anemia and vaso-occlusion. ${ }^{2}$ HOE sign is one such complication which results from accentuated vertical trabeculae between the inner and outer table of the skull because of excessive bone marrow hyperplasia which is extensively used as an ancillary hematopoietic organ to compensate for the chronic hemolysis. ${ }^{1}$ This sign has also been described in iron deficiency anemia, cyanotic heart disease, congenital syphilis, metastatic neuroblastoma, nutritional deficiencies, as well as hematologic malignancies. ${ }^{4,5}$ Here, we discuss HOE sign in a 9-year old-girl with a previously 
missed diagnosis of sickle cell disease who presented with acute hemorrhagic stroke. Our discussion will focus on the incidental finding of the HOE sign.

\section{Case Presentation}

\section{Presenting Symptoms}

A 9-year old-girl presented with a 2-day history of acute onset headache and vomiting; the symptoms worsened by the end of the second day, culminating in an altered level of consciousness and unilateral fits.

\section{Past Medical History}

The patient's mother reported a history of easy fatigability and long-standing yellowing of the eyes. This was reportedly the girls' fourth hospital admission this year, with all previous admissions being due to febrile illnesses and unexplained body aches. She received a blood transfusion on two separate occasions but the mother had no memory of the drugs administered during those admissions. The availed previous discharge papers had no documentation confirming SCD.

\section{Family and Social History}

The child is the second born of five children, the fourth born died of "bone pain" and anemia; no specific diagnosis was known to the parents. One of the paternal uncles reportedly died of anemia at the age of 11 years. The rest of the siblings are thriving normally.

\section{Physical Examinations}

On physical examination, she had frontal bossing with a prominent occiput, severe pallor of the conjunctivae, mild scleral icterus and felt febrile to touch, with a temperature of $37.8^{\circ} \mathrm{C}$. Her pulse rate was 98 beats per minute with normal heart sounds. Her respiratory rate was at 34 breaths per minute and her chest had normal vesicular breath sounds on auscultation, with oxygen saturation of $98 \%$ on 2 liters of oxygen. The abdominal exam revealed hepatosplenomegaly. There was mild facial deviation to the left on neurological exam with a GCS of 9/15; stiff neck with a positive kernig's sign. The activity in the left upper and lower limbs was reduced, however, the deep tendon reflexes were normal. There was no obvious bone tenderness.

\section{Investigations}

\section{Full Haemogram}

Complete blood count revealed a typical picture seen in sickle cell disease. There was an elevation in total leukocyte and platelet counts, while the hemoglobin and red cell counts were decreased, as represented in Table 1.

Hemoglobin electrophoresis analysis revealed the following hemoglobin fractions; $\mathrm{Hb} \mathrm{F} 7.2 \%, \mathrm{Hb} \mathrm{A} 23.7 \%$ and $\mathrm{Hb}$ S $89.1 \%$, consistent with sickle cell disease.

Table I Full Haemogram as at Admission

\begin{tabular}{|l|l|l|}
\hline Parameter & Result & Reference ranges \\
\hline Leukocytes & $35.36\left(10^{\wedge} 3 / \mu \mathrm{L}\right)$ & $6.00-14.00$ \\
\hline Erythrocytes & $1.79\left(10^{\wedge} 6 / \mu \mathrm{L}\right)$ & $4.00-5.20$ \\
\hline Hemoglobin & $6.1(\mathrm{~g} / \mathrm{dL})$ & $11.5-15.5$ \\
\hline Platelets & $451\left(10^{\wedge} 3 / \mu \mathrm{L}\right)$ & $150-400$ \\
\hline
\end{tabular}

Note: Note the elevated total leukocyte and platelet count with decreased hemoglobin and red cell. 


\section{CT-Scan}

The patient was referred to the radiology unit for a head CT. With the patient in supine position on the table, images were acquired from the skull base to the cranial vault using a 16 slice Siemens CT scan machine at a slice thickness of $5 \mathrm{~mm}$ and reconstructed at $1 \mathrm{~mm}$. The scan demonstrated right cerebral intraparenchymal hemorrhage, multiple high cerebral infarcts on the right, and evidence of extra medullary hematopoiesis with a classical HOE sign (Figure $1 \mathrm{~A}$ and $\mathrm{B}$ ).

\section{Management}

The patient was managed for acute stroke in chronic sickle cell disease (newly diagnosed). She received two units of whole blood and a nasogastric tube was inserted through which she was fed. She was initiated on hydroxyurea, intravenous antibiotic cover (ceftriaxone, metronidazole), as meningitis was initially among the differentials in view of the stiff neck, morphine, and intravenous saline. She also had daily reviews by the physiotherapists. The patient improved and was discharged 16 days post-admission on Hydroxyurea, Folic acid, Sulfadoxine/Pyrimethamine combination tablets. Her hemoglobin had improved from $6.1 \mathrm{~g} / \mathrm{dL}$ to $9.4 \mathrm{~g} / \mathrm{dL}$.

\section{Follow-Up}

The patient was scheduled for a review in 2 weeks time but could only afford to return 2 months later due to financial constraints. No new complaints were registered during her first review. Full haemogram results are indicated in Table 2.

\section{Discussion}

"HOE" is a rare sign seen in the diploic spaces on skull radiographs having the appearance of long, thin vertical striations perpendicular to the skull tables resembling hairs standing on ends. ${ }^{6}$ This sign has been classically observed and reported on plain radiography; however, it can also be demonstrated on CT and MRI. ${ }^{7}$ In this case, the diagnosis was made on CT. HOE sign in our case was an incidental finding on CT.

HOE sign is majorly seen in children over the age of 5 years of age with hemolytic anemias, that is; thalassemia and sickle cell disease. ${ }^{8,9}$ Our case was of a 9 year old girl in whom the diagnosis of SCD had been missed several times, giving room for this musculoskeletal complication to arise. HOE sign has been reported to have a prevalence of $5 \%$ in skull radiographs of 194 patients with sickle cell anemia. ${ }^{10}$ Peripheral destruction of erythrocytes with resultant decreased oxygenation of arterial blood lead to profuse hyperplasia and widening of the medullary cavity of the hematopoietic bone marrow in these conditions. ${ }^{11}$ The hyperplastic marrow, which is extensively used as an ancillary hematopoietic organ to compensate for the chronic hemolysis leads to widening of the medullary cavity, causing expansion of the diploic space. The expanding marrow eventually causes pressure atrophy, leading to radial arrangement of the trabecular elements at right
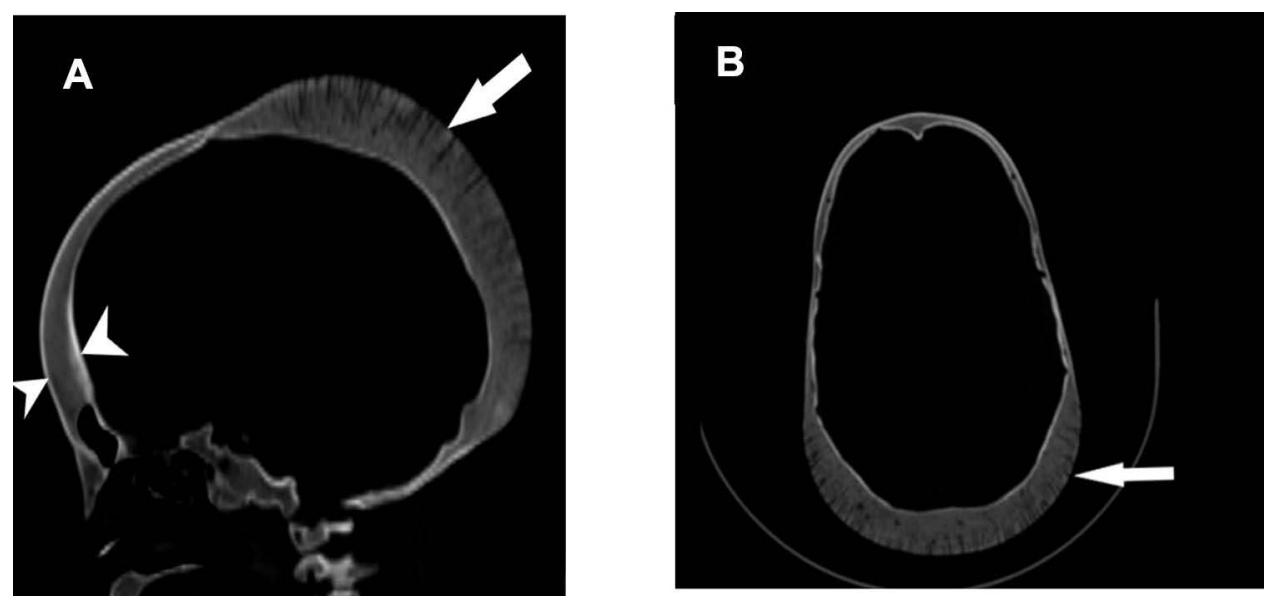

Figure I (A) Sagittal head CT in bone window demonstrating widened diploic space (arrow heads) with hair on end pattern (arrow). (B) Hair on end pattern in axial plane (arrow). 
Table 2 Full Haemogram at First Review 2 Months Later

\begin{tabular}{|l|l|l|}
\hline Parameter & Result & Reference ranges \\
\hline Leukocytes & $11.31\left(10^{\wedge} 3 / \mu \mathrm{L}\right)$ & $6.00-14.00$ \\
\hline Erythrocytes & $2.01\left(10^{\wedge} 6 / \mu \mathrm{L}\right)$ & $4.00-5.20$ \\
\hline Hemoglobin & $7.4(\mathrm{~g} / \mathrm{dL})$ & $1.5-15.5$ \\
\hline Platelets & $636\left(10^{\wedge} 3 / \mu \mathrm{L}\right)$ & $150-400$ \\
\hline
\end{tabular}

Notes: The Leukocyte count had normalized. There was improvement in erythrocyte and hemoglobin count though they were still low. The platelet count increased far beyond the reference range.

angles to the tables, generating the HOE sign as seen on conventional radiographs, CT, and MRI. ${ }^{12,13}$ The common presentation is with headaches usually attributed to periosteal pain due to marrow expansion. ${ }^{14}$ Our patient reportedly had a history of long-standing headache prior to the stroke. This musculoskeletal complication of HOE sign should be considered in patients with suspected or confirmed SCD having long-standing headaches, especially in low resource settings where primary healthcare is barely available to allow for a timely diagnosis and initiation of management.

It has been reported that the maintenance of hemoglobin level above $10 \mathrm{~g} / \mathrm{dL}$ can prevent the development of this musculoskeletal complication and, due to improved blood transfusion in patients with hemolytic anemias, HOE has been encountered with progressively reduced frequency and severity nowadays. ${ }^{15,16} \mathrm{HOE}$ sign is therefore an indicator of poorly managed SCD and is more frequently seen in inadequately transfused patients especially in resource-poor areas as was the case with our patient whose hemoglobin was $6.1 \mathrm{~g} / \mathrm{dL}$ as at admission. It is still controversial whether the HOE sign can be reversed to a certain degree following treatment of the anemia. ${ }^{17}$

\section{Conclusion}

HOE sign of the skull is a characteristic feature of chronic hemolysis usually seen in patients with thalassemia and sickle cell anemia. This sign has been classically observed and reported on plain radiography; however, it can also be identified as demonstrating the same appearance on CT and MRI. HOE sign is likely to be more common in regions where individuals may not have easy access to consistent medical care with consequent poor management of SCD cases. Knowledge of this rare skeletal manifestation of chronic hemolytic anemia is important for both Clinicians and Radiologists to be armed with as it is suggestive of poor management of SCD.

\section{Data Sharing Statement}

The information used and/or analyzed during this case report is available from the corresponding author on reasonable request.

\section{Ethics}

Ethical clearance was obtained from Mbarara University Faculty of Medicine Research Committee. The patient's parent or legal guardian provided informed consent for the case details to be published.

\section{Informed Consent}

The mother provided informed consent prior to imaging and other investigations.

\section{Acknowledgment}

Radiology, Surgery, Paediatrics and Child Health Departments of Mbarara University and the study participant.

\section{Disclosure}

The authors declare no conflicts of interest in this work. 


\section{References}

1. Kennedy DP, Hooker JD, Morris RW. Osseous findings in sickle cell disease. Appl Radiol. 2020;49(2):30-34.

2. Vichinsky EP, Mahoney D Jr. Diagnosis of Sickle Cell Disorders. Waltham (MA): UpToDate; November, 2019.

3. Schkrohowsky JG, Hoernschemeyer DG, Carson BS, Ain MC. Early presentation of spinal stenosis in achondroplasia. J Pediatr Orthop. 2007;27 (2):119-122. doi:10.1097/01.bpb.0000248570.50875.28

4. Walor DM, Berdon WE, Westra SJ. 'Hair-on-end'skull changes resembling thalassemia caused by marrow expansion in uncorrected complex cyanotic heart disease. Pediatr Radiol. 2005;35(7):698-701. doi:10.1007/s00247-005-1403-0

5. Britton HA, Canby JP, Kohler CM. Iron deficiency anemia producing evidence of marrow hyperplasia in the calvarium. Pediatrics. 1960;25:621-628. doi:10.1542/peds.25.4.621

6. Basu S, Kumar A. Hair-on-end appearance in radiograph of skull and facial bones in a case of beta thalassaemia. Br J Haematol. $2009 ; 144(6): 807$. doi:10.1111/j.1365-2141.2008.07404.x

7. Martin L, Rackard F. Hair-on-end sign. N Engl J Med. 2016;374(19):e23. doi:10.1056/NEJMicm1510045

8. Balikar R, Redkar NN, Patil MA, Pillai R. Hair-on-end appearance in a case of thalassemia intermedia. Case Rep. 2013;2013:bcr2012008095.

9. Chen T-H, Yang S-N. Hair-on-end skull in an infant without anemia. J Pediatr. 2012;161(2):367. doi:10.1016/j.jpeds.2012.03.041

10. Sebes JI, Diggs L. Radiographic changes of the skull in sickle cell anemia. Am J Roentgenol. 1979;132(3):373-377. doi:10.2214/ajr.132.3.373

11. Hollar MA. The hair-on-end sign. Radiology. 2001;221(2):347-348. doi:10.1148/radiol.2212991231

12. Resnick D, Niwayama G. Diagnosis of Bone and Joint Disorders. Vol. 1-6 Scientific Research. 1988.

13. Nagaraj T, Umashree N, Devarhubli AR, Shankara S. $\beta$ Thalassemia major: a case report. J Int Oral Health. 2011;3(5):67.

14. Albert MH, Notheis G, Wintergerst U, Born C, Schneider K. "Hair-on-end" skull induced by long-term G-CSF treatment in severe congenital neutropenia. Pediatr Radiol. 2007;37(2):221-224. doi:10.1007/s00247-006-0363-3

15. Hajimoradi M, Haseli S, Abadi A, Chalian M. Musculoskeletal imaging manifestations of beta-thalassemia. Skeletal Radiol. 2021;1-14. doi:10.1007/s00256-020-03533-6

16. Petrocheilou G, Doulgeraki A, Polyzois G, et al. Radiographic skeletal features of beta-thalassemia: pictorial essay and background etiology. In: Seminars in Musculoskeletal Radiology. Thieme Medical Publishers, Inc; 2021.

17. Taher AT, Musallam KM, Cappellini MD, Weatherall DJ. Optimal management of $\beta$ thalassaemia intermedia. Br J Haematol. 2011;152 (5):512-523. doi:10.1111/j.1365-2141.2010.08486.x

\section{Publish your work in this journal}

The International Medical Case Reports Journal is an international, peer-reviewed open-access journal publishing original case reports from all medical specialties. Previously unpublished medical posters are also accepted relating to any area of clinical or preclinical science. Submissions should not normally exceed 2,000 words or 4 published pages including figures, diagrams and references. The manuscript management system is completely online and includes a very quick and fair peer-review system, which is all easy to use. Visit http://www.dovepress.com/testimonials. php to read real quotes from published authors.

Submit your manuscript here: https://www.dovepress.com/international-medical-case-reports-journal-journal 